\title{
A Rare Location of Angiofibroma in the Inferior Turbinate in Young Woman
}

\author{
Asif Salimov ${ }^{1}$ Serdar Ozer ${ }^{1}$ \\ ${ }^{1}$ Department of Otolaryngology, Hacettepe University Hospital, \\ Ankara, Turkey \\ Int Arch Otorhinolaryngol 2015;19:187-190.
}

\begin{abstract}
Address for correspondence Asif Salimov, MD, Department of Otolaryngology, Hacettepe University Hospital, Sihhiye, Ankara 06100, Turkey (e-mail: asifselimov2003@hotmail.com; asifselimov2003@yahoo.com).
\end{abstract}

\begin{abstract}
Keywords

- extranasopharyngeal angiofibroma

- epistaxis

- inferior turbinate

Introduction Juvenile nasopharyngeal angiofibroma is a rare benign neoplasm in the nasopharynx. The tumor tends to be locally aggressive and is typically seen in adolescent boys. Extranasopharyngeal angiofibromas have been reported sporadically in the literature. They most commonly originate from the maxillary sinus.

Objectives A 26-year-old woman was referred to our clinic with intermittent epistaxis from the right nasal passage for the previous 2 months. Maxillofacial magnetic resonance imaging showed a lobular, contoured mass originating from the right inferior turbinate and hanging in the right nasal cavity, with dense contrast enhancement denoting hypervascularity.

Resumed Report Vascular feeding of the mass was seen from the right internal maxillary artery with angiography, and this branch was embolized. On the following day, the patient underwent transnasal endoscopic excision of the mass. An approximately 3$\mathrm{cm}$-diameter mass was excised by partial turbinectomy, and the posterior edge of the remaining turbinate was cauterized.

Conclusion Extranasopharyngeal angiofibromas are rarely seen, and the inferior turbinate is an extremely rare location for them. This young woman is the first case reported in the English literature of angiofibroma originating from the inferior turbinate. We should consider these neoplasms can be found in female, nonadolescent patients with extranasopharyngeal localization, and we should not perform biopsy because of its massive bleeding.
\end{abstract}

\section{Introduction}

Juvenile nasopharyngeal angiofibroma (JNA) is a rare benign neoplasm in the nasopharynx. The tumor tends to be locally aggressive and is typically seen in adolescent boys. It arises from the superior margin of the sphenopalatine foramen and accounts for $0.05 \%$ of all head and neck neoplasms. The typical histopathologic appearance of JNA is numerous wide, irregular vessels with a single layer of endothelial cells embedded in fibrous stroma. The abundant vascular component is responsible for the excessive bleeding during surgery or following biopsies. ${ }^{1}$
Extranasopharyngeal angiofibromas (ENAs) have been reported sporadically in the literature. They most commonly originate from the maxillary sinus, and women are affected. Compared with nasopharyngeal fibromas, the lesion is diagnosed earlier, is less vascularized, and occurs in older patients. $^{2}$ Similar to JNAs, the treatment of choice for ENAs is surgery. Radiotherapy may be used for unresectable lesions. The surgical approach is tailored to the location and size of tumor. ${ }^{1}$ In our case, the tumor was small enough for total excision with an endonasal endoscopic approach. This is the first case report in the English literature of angiofibroma received

May 29, 2014

accepted

November 25, 2014

published online

December 29, 2014
DOI http://dx.doi.org/

10.1055/s-0034-1398471. ISSN 1809-9777.
Copyright (c) 2015 by Thieme Publicações License terms Ltda, Rio de Janeiro, Brazil 
originating in the inferior turbinate in a young woman. Preoperative embolization makes surgery more feasible.

\section{Review of the Literature with Differential Diagnosis}

ENAs are rarely seen, and the inferior turbinate is an extremely rare location for them. There are reports in the English literature of inferior turbinate angiofibroma in male patients. ${ }^{3-6}$ In female patients, there is only one case report in the English literature of inferior turbinate angiofibroma in a 52-year-old woman. ${ }^{7}$ Recently, a report was published of a 9-year-old girl with angiofibroma obstructing the nasal cavity and originating from the inferior turbinate. ${ }^{8}$

Differential diagnosis includes fibrosed antrochoanal and ethmoidal polyp and other fibrovascular tumors, such as capillary hemangioma, hemangiopericytoma, and solitary fibrous tumor. ${ }^{3}$

\section{Case Report}

A 26-year-old woman was referred to our clinic with intermittent epistaxis from the right nasal passage for the previous 2 months. Physical examination revealed a mass originating from the posterior right inferior turbinate. Maxillofacial magnetic resonance imaging showed a lobular, contoured mass originating from the right inferior turbinate and hanging to the right of the nasal cavity, with dense contrast enhancement denoting hypervascularity (-Figs. 1, 2, and 3). We decided to embolize the vascular feeding of the mass to make surgery more feasible. The patient consulted with the Invasive Vascular Radiology Department and decided on the embolization process under intravenous sedation. Vascular feeding of the mass was seen from the right internal maxillary artery, and this

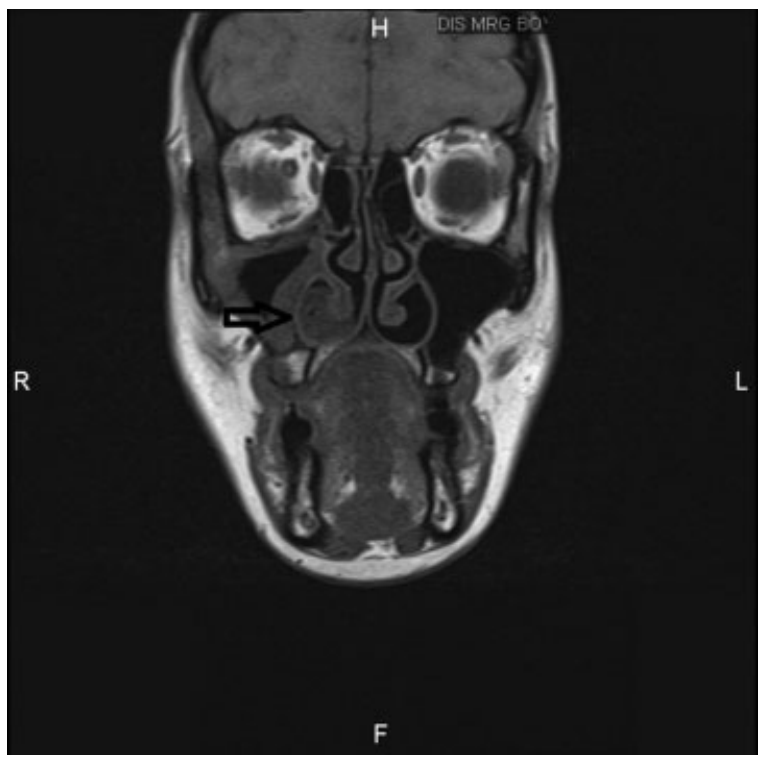

Fig. 1 Preoperative maxillofacial magnetic resonance imaging (coronal T1-weighted). Arrow shows the mass originating from the right inferior turbinate.

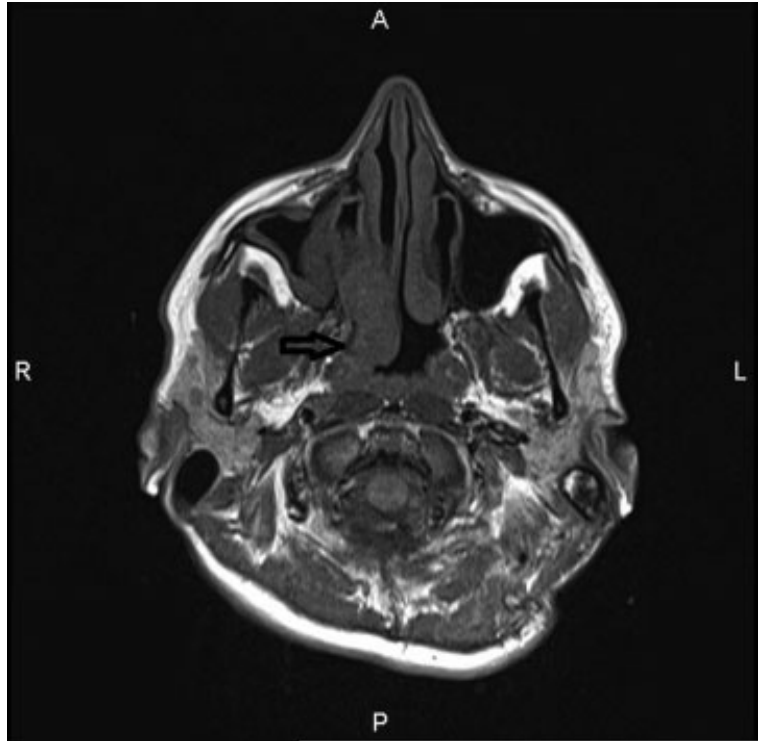

Fig. 2 Preoperative maxillofacial magnetic resonance imaging (axial T1-weighted). Arrow shows the mass originating from the right inferior turbinate.

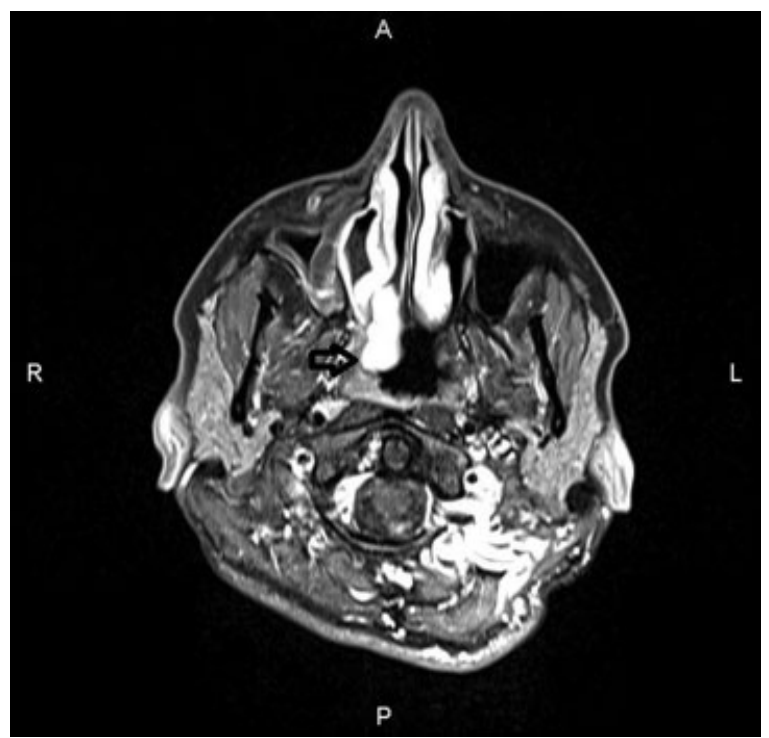

Fig. 3 Preoperative maxillofacial magnetic resonance imaging (axial T1-weighted postcontrast). Arrow shows dense contrast enhancement of the mass.

branch was embolized. The following day the patient underwent transnasal endoscopic surgery for excision of the mass. The procedure was performed under general anesthesia starting with uncinectomy. After that, the maxillary sinus ostium was found and widened. When looking at the posterior wall of the sinus and pterygopalatine fossa, no masslike structure was evident. The approximately 3-cm-diameter mass originated from the posterior edge of the right inferior turbinate (-Fig. 4). A partial turbinectomy was performed, and the posterior edge of the remaining turbinate was cauterized. The operation ended with a sponge gel filling in the right middle meatus. 


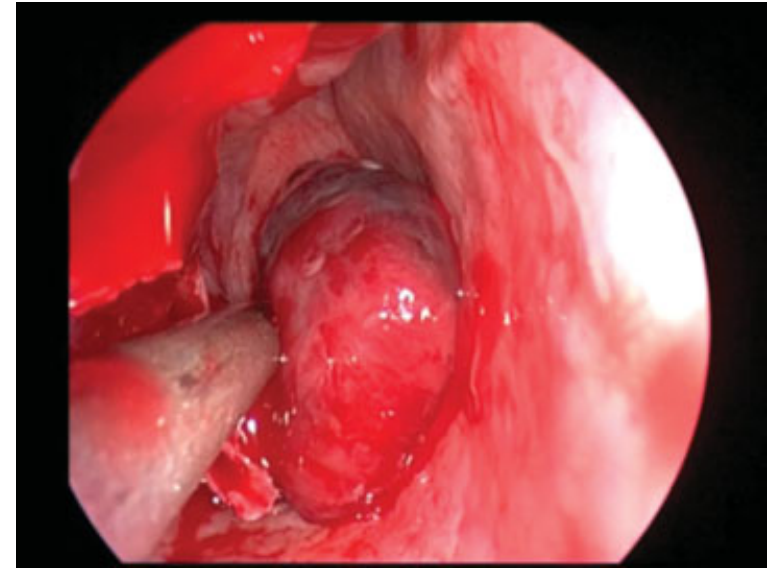

Fig. 4 Intraoperative view of the lesion.

There was no evidence of recurrence in the following 13 months.

\section{Discussion}

A mean age of 20 to 30 years in ENAs was found in the literature. ${ }^{1,2,9}$ Our case was also in this group.

ENAs mostly originate from the maxillary sinus. ${ }^{2}$ There are also some reports of tumors located in the ethmoid sinus, nasal cavity, nasal septum, larynx, sphenoid sinus, cheek, conjunctiva, oropharynx, retromolar area, and middle turbinate. $3,10-16$

The clinical presentation of ENAs depends on tumor localization. In our case, the clinical presentation was similar to JNAs. But because of the limited space in the nasal cavity, diagnosis was made at an early tumor stage.

The cause of inferior turbinate angiofibroma is not well understood. The tumor's location indicated that the origin may be from ectopic tissues located further from its usual place. ${ }^{17}$

There is also a reported case of an angiofibroma arising from the inferior turbinate after $\mathrm{CO}_{2}$ laser turbinoplasty. ${ }^{18}$ In our case, there was no history of turbinate surgery.

Selective angiography is a useful diagnostic method to demonstrate tumor vascular composition and to confirm the diagnosis. It also allows tumor embolization, which reduces intraoperative bleeding. ${ }^{1}$

\section{Final Comments}

ENA in a young woman is a very rare clinical entity. Endoscopic and radiologic examination is important, but definitive diagnosis is made by histopathologic analysis. We should consider these neoplasms possibly in female patients, at every age, with extranasopharyngeal localization, and we should not perform biopsy because of massive bleeding. Preoperative embolization of the vessels makes surgery more feasible.

\section{References}

1 Szymańska A, Szymański M, Morshed K, Czekajska-Chehab E, Szczerbo-Trojanowska M. Extranasopharyngeal angiofibroma: clinical and radiological presentation. Eur Arch Otorhinolaryngol 2013;270(2):655-660

2 Windfuhr JP, Remmert S. Extranasopharyngeal angiofibroma: etiology, incidence and management. Acta Otolaryngol 2004; 124(8):880-889

3 Nomura K, Shimomura A, Awataguchi T, Murakami K, Kobayashi T. A case of angiofibroma originating from the inferior nasal turbinate. Auris Nasus Larynx 2006;33(2):191-193

4 Celik B, Erisen L, Saraydaroglu O, Coskun H. Atypical angiofibromas: a report of four cases. Int J Pediatr Otorhinolaryngol 2005; 69(3):415-421

5 Taggarshe D, Quraishi MS, Dugar JM. Inferior turbinate angiofibroma: an atypical presentation [correction of preservation]. Rhinology 2004;42(1):45-47

6 Gaffney R, Hui Y, Vojvodich S, Forte V. Extranasopharyngeal angiofibroma of the inferior turbinate. Int J Pediatr Otorhinolaryngol 1997;40(2-3):177-180

7 Lee JH, Jeong HM. Extranasopharyngeal angiofibroma originating in the inferior turbinate. Ear Nose Throat J 2013;92(9):E31-E32

8 Baptista MAFB, Pinna FR, Voegels RL. Extranasopharyngeal angiofibroma originating in the inferior turbinate: a distinct clinical entity at an unusual site. Int Arch Otorhinolaryngol 2014; 18:403-405

9 Huang RY, Damrose EJ, Blackwell KE, Cohen AN, Calcaterra TC. Extranasopharyngeal angiofibroma. Int J Pediatr Otorhinolaryngol 2000;56(1):59-64

10 Somdas MA, Ketenci I, Unlu Y, Canoz O, Guney E. Extranasopharyngeal angiofibroma originating from the nasal septum. Otolaryngol Head Neck Surg 2005;133(4):647

11 Dere H, Ozcan KM, Ergul G, Bahar S, Ozcan I, Kulacoglu S. Extranasopharyngeal angiofibroma of the cheek. J Laryngol Otol 2006; 120(2):141-144

12 Tasca I, Compadretti GC. Extranasopharyngeal angiofibroma of nasal septum. A controversial entity. Acta Otorhinolaryngol Ital 2008;28(6):312-314

13 Mohindra S, Grover G, Bal AK. Extranasopharyngeal angiofibroma of the nasal septum: a case report. Ear Nose Throat J 2009;88(11): E17-E19

14 Tsunoda A, Kohda H, Ishikawa N, Komatsuzaki A. Juvenile angiofibroma limited to the sphenoid sinus. J Otolaryngol 1998;27(1):37-39

15 Steele MH, Nuss DW, Faust BF. Angiofibroma of the larynx: report of a case with clinical and pathologic literature review. Head Neck 2002;24(8):805-809

16 Handa KK, Kumar A, Singh MK, Chhabra AH. Extranasopharyngeal angiofibroma arising from the nasal septum. Int J Pediatr Otorhinolaryngol 2001;58(2):163-166

17 Perić A, Baletić N, Cerović S, Vukomanović-Durdević B. Middle turbinate angiofibroma in an elderly woman. Vojnosanit Pregl 2009;66(7):583-586

18 Kang JW, Kim YH, Kim JH. Angiofibroma of inferior turbinate as an unusual complication of CO2 laser turbinoplasty. J Craniofac Surg 2013;24(5):e513-e514 